\title{
Effect of human pegivirus route of transmission on the genetic distribution of the virus: an institution based cross- sectional study
}

\author{
Wubet Taklual ${ }^{*}$, Shixing Tang ${ }^{2}$ and Wu Yue 2,3
}

\begin{abstract}
Introduction: Human pegivirus (HPgV), formally called GB virus C (GBV-C), is a member of the pegivirus genus in Flaviviridae family. High prevalence of HPgV infection is seen among sex workers, blood transfusion recipients and intravenous drug users (IDUs). So far, there are seven genotypes and many subtypes identified in different countries. The predominant genotype in Asia including China is genotype 3, although genotype 7 has been reported recently in China. The aim of this study was to evaluate the effect of the transmission routes of HPgV infection on the genotype distribution of the virus, to determine the prevalence rate, and identify the dominant genotype among men who have sex with men (MSM) and IDUs co-infected with human immunodeficiency virus type one (HIV-1) in Guangzhou, China.
\end{abstract}

Methods: A total of 131 MSM and 70 IDUs co-infected with HIV-1 were randomly selected in Guangdong Dermatology Hospital. HPgV RNA was detected by nested reverse transcriptase polymerase chain reaction (RT-PCR) using primers. The PCR products were sequenced and phylogenetically analyzed by using MEGA6.06 version software to determine the genotypes. Chi-square and Fisher exact test were implemented for comparing the proportion between different variables.

Results: The prevalence of HPgV infection was 32.9\% among IDUs and 18.3\% in MSM with a statistically significant difference between the two groups ( $p=0.02$ ). In IDU group, 82.6\% infected with genotype 3 and the rest (17.4\%) were categorized to genotype 7. Similarly, in MSM group, 83.3\% belonged to genotype 3, and the remaining $16.7 \%$ were classified as sub-genotype $2 \mathrm{a}$ and $2 \mathrm{~b}$.

Conclusion: In Guangzhou, China, the prevalence rate of HPgV infection in IDUs was higher than MSM. The dominant genotype in the two groups was genotype 3. Our results indicated that routes of transmission did not affect the genotype distribution but did affect the prevalence rate of HPgV infection.

Keywords: HPgV, Intravenous drug users, Men who have sex with men, Genotype, Route of transmission, China

\footnotetext{
* Correspondence: wubettaklual21@yahoo.com

'Department of Population Health, College of Health Sciences, Debre Tabor

University, Post office box: 272, Debre Tabor, Ethiopia

Full list of author information is available at the end of the article
}

(c) The Author(s). 2019 Open Access This article is distributed under the terms of the Creative Commons Attribution 4.0 International License (http://creativecommons.org/licenses/by/4.0/), which permits unrestricted use, distribution, and reproduction in any medium, provided you give appropriate credit to the original author(s) and the source, provide a link to the Creative Commons license, and indicate if changes were made. The Creative Commons Public Domain Dedication waiver (http://creativecommons.org/publicdomain/zero/1.0/) applies to the data made available in this article, unless otherwise stated. 


\section{Background}

Human PegiVirus (HPgV), formally called GB Virus C $(\mathrm{GBV}-\mathrm{C})$, is a member of pegivirus genus with in the family of Flaviviridae. It is a single stranded RNA virus and contains a single open reading frame (ORF). $\mathrm{HPgV}$ and hepatitis $\mathrm{C}$ virus $(\mathrm{HCV})$ share some similar features although they belong to different genera [1-3]. So far, HPgV has been classified into seven genotypes and many subtypes. The distribution of $\mathrm{HPgV}$ genotypes varies across different countries of the world: genotype 1 mainly in West Africa, genotype 2 in America and Europe, genotype 3 in Asia, genotype 4 in South East Asia in particular in Vietnam, genotype 5 only in South Africa, and genotype 6 predominantly in Indonesia. Genotype 7 has recently been described in Yunnan Province, China [4-10].

Sexual contacts, injecting drugs, blood transfusion, parenteral exposure, and medical procedures have been documented as the main transmission routes of $\mathrm{HPgV}$ [11-15]. High prevalence rate was seen in MSM and IDUs [16-18]. Co-infection of HPgV and HIV-1 and/or $\mathrm{HCV}$ is common. The rate of triple infection of $\mathrm{HPgV} /$ $\mathrm{HIV}-1 / \mathrm{HCV}$ was even higher than the dual infection of $\mathrm{HPgV} / \mathrm{HIV}-1[4,16]$.

The prevalence of $\mathrm{HPgV}$ varies in different countries and among the various subjects. The $\mathrm{HPgV}$ prevalence was reported to be as low as $0.13 \%$ among a healthy blood donors in China, whereas $88.8 \%$ of the HIV-1 positive patients were infected with $\mathrm{HPgV}$ in Indonesia $[8,19]$. In China, high prevalence of $\mathrm{HPgV}$ infection was seen among IDUs and MSM $[4,9,20]$.

Previous studies also indicate that $\mathrm{HPgV}$ prevalence is affected by route of transmission and co-infections with hepatitis B virus (HBV), HCV, and HIV-1. In addition, parenteral and sexual transmissions were the major mode of transmission of $\mathrm{HPgV}$ [8, 12, 17, 19, 21-26]. Although there were many studies to report $\mathrm{HPgV}$ infection in different population and countries, little is known whether the transmission route of $\mathrm{HPgV}$ affects its genetic diversity or not. Previous studies indicated that the dominant genotype of HPgV in China was genotype 3. However, in Yunnan Province, China, the majority of the IDUs infected with $\mathrm{HPgV}$ genotype 7 whereas, in Beijing MSM was mainly infected with $\mathrm{HPgV}$ genotype 3 [4, 9]. Therefore, these preliminary results may raise a question whether the routes of transmission or different risk population has an effect on the genotype distribution of HPgV. In addition, relatively higher prevalence $(0.89 \%)$ of $\mathrm{HPgV}$ infection was reported in general population in Southern China [20]. Guangzhou is part of Southern China, but few information was available about $\mathrm{HPgV}$ prevalence among MSM and IDUs. Thus, the aim of this study was to evaluate the effect of route of transmission on the genotype distribution of $\mathrm{HPgV}$, to determine the prevalence rate, and to identify the dominant genotypes among the two high risk populations.

\section{Material and methods}

Institutional based cross-sectional study was conducted among MSM and IDUs infected with HIV-1, who attended in Guangdong Dermatology Hospital. A total of $131 \mathrm{MSM}$ and 70 IDUs infected with HIV-1 were randomly included in the study. The participants were selected based on the screening results of HIV-1.

A structured and pretested questionnaire was completed by trained data collector in face to face interview. The questionnaires were developed and completed in Chinese language, then translated to English for analysis by another language expert personnel for its consistency.

\section{Ethical clearance}

Ethical clearance was obtained from the Research Review Committee from Guangdong Dermatology Hospital. The participants were enrolled in the study after obtaining written consent. De-linked data and samples were used for analysis in our study.

\section{Blood sample collection and processing}

Five microliters of blood sample was taken from each participant using vacuum tube. The plasma was separated by using centrifugation and kept at $-70^{\circ} \mathrm{C}$ until analysis.

\section{RNA extraction}

Viral RNA was extracted from $140 \mathrm{ul}$ of plasma sample by using commercially available QIA amp Viral RNA mini kit according to the manufacturer instruction.

\section{Amplification of nested one-step RT-PCR}

The Amplification of PCR was performed with primers:

\section{5' -AGTGAGTTTTGGAGATGGACTGARCAG-3' in outer forward \\ 5'-GGGAAWGCYCCCCGAGCRAGCTTCCAC-3' in outer reverse \\ 5'-GTGTGAYTGCCCCAAYGGYCCCTGGGT-3' in inner forward \\ 5' - CCACARCACRAGRAACATBAGGCGYTG-3' in inner reverse}

using water as a negative control.

The first-round of PCR amplification was performed in $25 \mathrm{ul}$ of reaction volume. The reaction contains (PCR buffer, $\mathrm{MgCl} 2$, dNTP, outer forward and reverse primer, enzyme, and RNA). The reaction volume was the same as for the second-round. In the first-round $50^{\circ} \mathrm{C}$ for $30 \mathrm{~min}$, and $94^{\circ} \mathrm{C}$ for $2 \mathrm{~min}$ for reverse transcription, then $35 \mathrm{cy}$ cles of $94{ }^{\circ} \mathrm{C}$ for $30 \mathrm{~s}, 55^{\circ} \mathrm{C}$ for $30 \mathrm{~s}$, and $72{ }^{\circ} \mathrm{C}$ for $1 \mathrm{~min}$ were used for $\mathrm{cDNA}$ amplification. The amplification was also done for the second-round for further amplification at 35 cycles of $94{ }^{\circ} \mathrm{C}$ for $30 \mathrm{~s}, 55^{\circ} \mathrm{C}$ for $30 \mathrm{~s}$, and $72^{\circ} \mathrm{C}$ for one min. The amplified cDNA was separated by 
electrophoresis with $1 \%$ agarose gel then stained with ethidium bromide substitute dye and visualized by UV illuminator. In all procedures, the standard precautions were followed to avoid PCR contamination.

All Serological markers for HIV-1, HBV, HCV, and HSV-2 were detected by using enzyme -linked immunosorbent assay (ELISA) rapid testing kit. All tests were performed according to the manufacturer instructions.

\section{Nucleotide sequence determination and phylogenetic analysis}

The nucleotide sequences were determined by Invitrogen Company in China. Phylogenetic analysis was performed by using MEGA6.06 version software with the reference sequences, which were obtained from the GenBank of the U.S. National Center for Biotechnology Information (NCBI). Nucleotide sequence alignments were made by using CLUSTALW. The phylogenetic tree was constructed by using the maximum likelihood method under the appropriate nucleotide substitution model. Bootstrapping was performed on 1000 re-samplings of the alignments. Genotyping was implemented by using blast with at least five high homology reference sequences for each nucleotide sequence. The reference sequences used for analysis from the GenBank were; HPgV genotype 1 (AB013500, U36380, MH053117, KC618399.1, AB003291, and AB008336), genotype 2 (U63715, LT009489, D87255, AF121950, MH053116.1, MH053115.1, KP259281, AY196904.1, and U44402), genotype 3 (D90601, D87263, U75356, AF006500, D87712, AB003288, U94695, AB008335, AF017532.1, MH746815.1, and D87708), genotype 4 (AB018667, and AB021287), genotype 5 (AY949771, KP710606, KC618401.1, and KC618398.1), genotype 6 (AB003292), genotype 7 (HQ331233, HQ331234, and HQ331235), and an outlier sequence AF070476.

\section{Recombination analysis}

Bootscanning analysis of E2 sequence was done to identify any recombination event by SimPlot version 3.5.1 using Kimura 2-parameter with a 200 base pair (bp), a 20 bp step increment, and 1000 bootstrap replicates [27]. Each E2 sequence was compared to consensus sequences generated using available GenBank references for genotypes $1(n=6), 2(n=9), 3(n=11), 4(n=2), 5$ $(n=4)$, and $7(n=3)$. Due to the limited availability of genotype 6, only reference AB003292 was used.. If $>70 \%$ of the permuted trees showed similarity to more than one genotype across the E2 region analyzed, the 'parental' sequences were retained within a second bootscanning analysis along with the outlier and the query sequence. The reported sequences in this study were submitted to the GenBank under the accession numbers MK686565 to MK686611.

\section{Statistical analysis}

All statistical analyses were performed by using SPSS version 21.0 software. Frequency and percentage were calculated using descriptive statistics. Chi-square and Fisher exact test were implemented for comparing the proportion between different variables. A $p$-value $<0.05$ was considered as statistically significant.

\section{Results}

Detection of HPgV RNA in IDUs and MSM population

To determine the prevalence of HPgV and the impact of route of transmission on the $\mathrm{HPgV}$ genetic diversity, a total of 201 IDUs and MSM infected with HIV-1 participants were recruited. Among them, 70 were IDUs and 131 were MSMs. HPgV RNA was identified in 47 samples. The prevalence of HPgV infection was $32.9 \%$ (23/70) and $18.3 \%$ (24/131) in IDUs and MSM, respectively. There was a statistically significant difference in the prevalence of HPgV infection between the two groups $(p=0.02)$.

\section{Socio-demographic characteristics and $\mathrm{HPgV}$ infection in the MSM}

The mean age of the participant was $28.9 \pm 6.1$ years. More than half of them (57.3\%) were between 21 and 30 years of age. Most of the participants were unmarried (87.3\%). Approximately two-third of them (63.6\%) had completed junior college. With regard to the occupational status of the participant, 27.8, 25.4, and $23.8 \%$ were business men, waiters, and cadres, respectively (see Table 1).

In this study, the highest $\mathrm{HPgV}$ prevalence was recorded among participants in the age group of 45-54 years (33.3\%) and those co-infected with HCV (33.3\%). HPgV was often detected in Han nationality (19.0\%), un-married (20.9\%), completing high school (21.4\%), and daily workers (28.6\%). However, no statistical significant difference was obtained, probably due to the relative small numbers of participants (see Table 1).

\section{Phylogenic analysis and genotyping of HPgV}

The Phylogenic tree was constructed using maximum likelihood with the general time reversible (GTR) model (Fig. 1). All the HPgV sequences identified in our study belong to genotype $2 \mathrm{a}, 2 \mathrm{~b}, 3$, and 7 (Table 2). Genotype 3 was the predominant strain. There was no statistical significance difference on the genotype distribution in both MSM (83.3\%) and IDUs $(82.6 \%)(p=0.94)$. Furthermore, $17.4 \%$ of IDUs infected with genotype 7 whereas, $16.7 \%$ of the MSM infected with genotype 2 . In this study no evidence of recombination was observed.

\section{Discussion}

A total of 201 IDUs and MSM infected with HIV-1 were recruited to determine the prevalence, genetic diversity, and impact of route of transmission on the genotype 
Table 1 Socio-demographic characteristics and HPgV infection in the MSM

\begin{tabular}{|c|c|c|c|c|}
\hline \multirow[t]{2}{*}{ Variables } & & \multirow[t]{2}{*}{ No. (\%) } & \multicolumn{2}{|c|}{ HPgV infection } \\
\hline & & & No. (\%) & $P$ value \\
\hline \multirow[t]{2}{*}{ Nationality } & Han nationality & $121(92.4)$ & $23(19.0)$ & 0.513 \\
\hline & Others & $10(7.6)$ & $1(10.0)$ & \\
\hline \multirow[t]{2}{*}{ Marital status } & Unmarried & $110(87.3)$ & $23(20.9)$ & 0.524 \\
\hline & Married & $16(12.7)$ & $1(6.3)$ & \\
\hline \multirow[t]{4}{*}{ Age } & $15-24$ & $33(25.2)$ & $2(6.1)$ & 0.170 \\
\hline & $25-34$ & 75 (57.3) & $18(24.0)$ & \\
\hline & $35-44$ & $20(15.3)$ & $3(15.0)$ & \\
\hline & $>45$ & $3(2.3)$ & $1(33.3)$ & \\
\hline \multirow[t]{4}{*}{ Educational Status } & Middle school & $12(9.3)$ & $2(16.7)$ & 0.669 \\
\hline & High school & $28(21.7)$ & $6(21.4)$ & \\
\hline & Junior college & $82(63.6)$ & $13(15.9)$ & \\
\hline & University & $7(5.3)$ & $1(14.3)$ & \\
\hline \multirow[t]{7}{*}{ Occupational status } & Daily worker & $7(5.6)$ & $2(28.6)$ & 0.714 \\
\hline & Farmer & $2(1.6)$ & - & \\
\hline & Solider & $7(5.6)$ & $1(14.3)$ & \\
\hline & Cadres & $30(23.8)$ & $6(20.0)$ & \\
\hline & Student & $13(10.3)$ & - & \\
\hline & Waiter & $32(25.4)$ & $6(18.8)$ & \\
\hline & Business man & 35 (27.8) & $5(14.3)$ & \\
\hline
\end{tabular}

distribution of $\mathrm{HPgV}$. In this study, the prevalence of HPgV infection in MSM and IDUs co- infected with HIV were $18.3 \%(24 / 131)$ and $32.9 \%$ (23/70), respectively. In our study the prevalence of HPgV among MSM is lower than that reported in previous studies $[9,17]$. The difference could be explained by the sample size difference, study area, and study period. The prevalence of $\mathrm{HPgV}$ among IDU co-infected with HIV is consistent with other similar studies [17, 21, 22, 28].

Different studies on the prevalence of HPgV infection in different groups of population in Japan, Australia, Eastern Europe, Denmark, Italy, and Argentina showed that the prevalence of $\mathrm{HPgV}$ was high in MSM and IDUs than other populations $[12,13,17,21,22,24,28-30]$. These results are in agreement with the present finding. This implies that the virus could be transmitted through both parenteral route and sex contacts.

In this study, the prevalence of $\mathrm{HPgV}$ infection shows statistically significant difference between the two study groups $(p=0.02)$, suggesting that parenteral route may be more efficient to transmit $\mathrm{HPgV}$ than sex contacts. However, the difference on socio-demographic variables, the prevalence of risky behaviors, such as unprotected anal intercourse with non-regular male partners and needle sharing behavior, and the presence of other co-infections may result in higher prevalence of $\mathrm{HPgV}$ in IDUs than MSM.

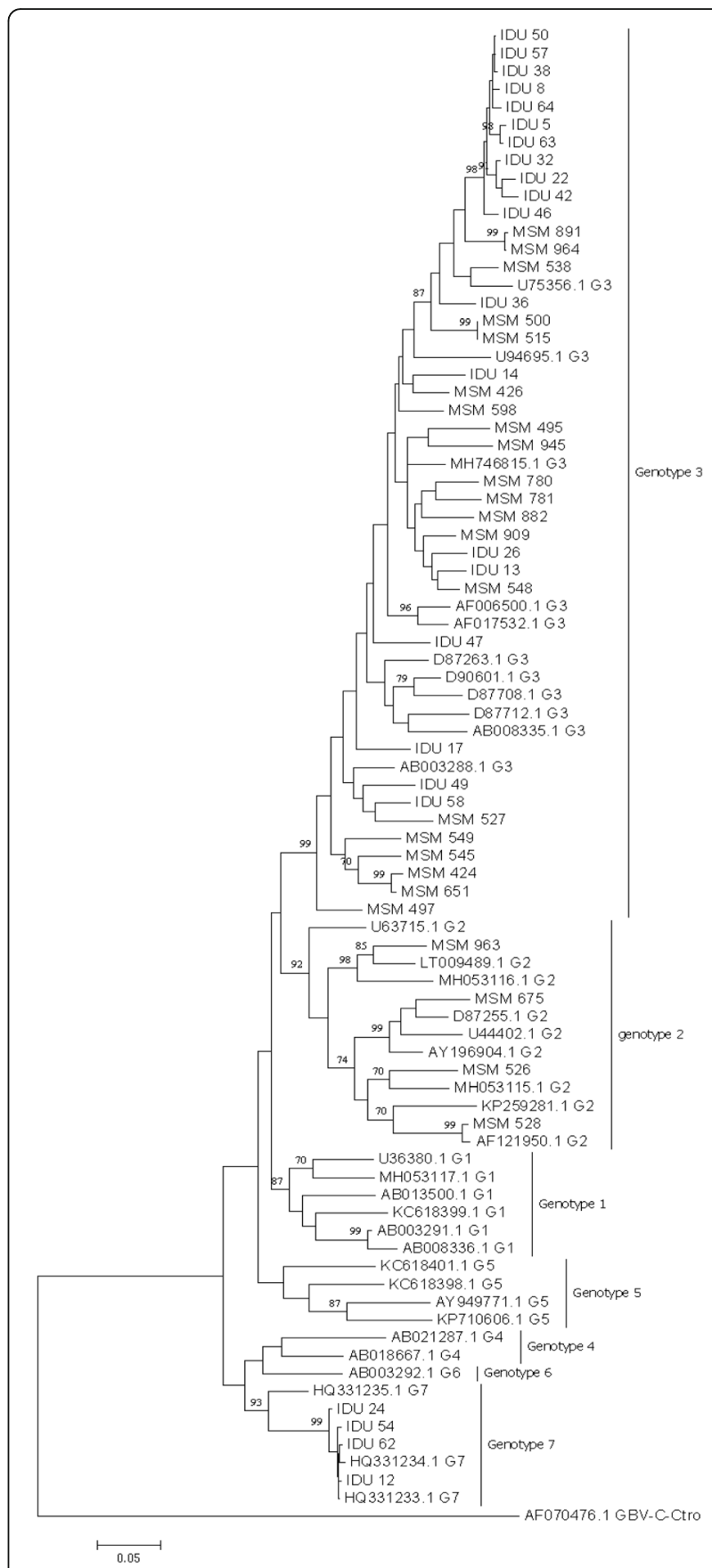

Fig. 1 Phylogenic tree analysis was developed based on HPgV E2 fragment. Forty seven sequences identified in the current study and additional 37 reference sequences from NCBI were included. The phylogenic tree was constructed using maximum likelihood method with the GTR model. The Bootstrap analysis was performed with 1000 replications, and the bootstrap probability (more than $70 \%$ ) was shown on the nodes. The scale bar represents $5 \%$ genetic distance (0.05 substitutions per site). The sequences labelled with MSM and IDU were identified in our study. The reference sequences for different HPgV genotypes were labelled with G1-G7 
Table 2 HPgV genotype distribution among MSM and IDUs

\begin{tabular}{|c|c|c|c|c|c|}
\hline \multirow{2}{*}{$\begin{array}{l}\mathrm{HPgV} \\
\text { infected- } \\
\text { participants }\end{array}$} & \multicolumn{4}{|c|}{ HPgV Genotype $(\mathrm{n}, \%)$} & \multirow{2}{*}{$\begin{array}{l}P \text { - } \\
\text { value }\end{array}$} \\
\hline & 3 & 7 & $2 a$ & $2 b$ & \\
\hline MSM $(n=24)$ & $20(83.3)$ & - & $3(12.5)$ & $1(4.2)$ & 0.947 \\
\hline IDUs $(n=23)$ & 19 (82.6) & $4(17.4)$ & - & - & \\
\hline Total $(n=47)$ & $39(83.0)$ & $4(8.5)$ & $3(6.4)$ & $1(2.1)$ & \\
\hline
\end{tabular}

HPgV genotyping analysis in MSM study group shows that $83.3 \%(20 / 24)$ of the sequences identified in our study belongs to genotype 3 . The finding is consistent with other previous studies in China and Japan [29, 31-33]. The rest of the sequences coincided with genotype $2 a / 2 b$, which were commonly seen in Europe and America [22, 30, 3436]. The distribution of HPgV genotype is in agreement with the previous study conducted in Beijing, China and Japan, in the same group of population [9, 29]. In contrast, HPgV genotype 2(2a, 2b) was rarely reported in China.

Previously in Yunnan province of China, the prevalence of HPgV infection in IDUs was 35.83\% (43/120). Of which $93 \%$ were described to be infected with genotype 7 and the rest $7 \%$ were infected with genotype 3 and 4 [4].In contrast, our finding indicated that in IDUs co-infected with HIV-1, 82.6\% (19/23) were classified to $\mathrm{HPgV}$ genotype 3 and the rest $17.4 \%$ were categorized in genotype 7 . The difference might suggest the distribution difference of $\mathrm{HPgV}$ genotypes in China. The finding of this study is supported by a previous studies conducted in other province of China and Japan in different group of population $[9,29,31-33]$. In this study, none of the sequences were classified as genotype 1,4 , and 6 , which were more frequently found in South Africa, Vietnam and Indonesia, respectively [5, 10, 37].

This study have some limitations. First, the study was conducted in small sample size, which may affect generalizability and representativeness of the findings. Second, all the study participants were HIV-1 infected participants, and lacked some clinical information (CD4-cell counts, HIV-1 viral load, etc.) and duration of infection.

\section{Conclusion}

The prevalence of $\mathrm{HPgV}$ infection was high among IDU than MSM in this study. The dominant genotype in the two groups was genotype 3, which is also predominant in Eastern Asian countries. In this study, we found that the route of transmission does not affect the genotype distribution of the virus but did affect the prevalence rate.

\footnotetext{
Abbreviations

ELISA: Enzyme-Linked Immunosorbent Assay; GTR: General TimeReversible; HBV: Hepatitis B Virus; HCV: Hepatitis C Virus; HIV: Human Immunodeficiency Virus; HPgV: Human pegivirus; HSV: Herpes Simplex Virus; IDU: Intra-venous Drug Users; MSM: Men who have Sex with Men; NCBI: National Center for Biotechnology Information; RT-PCR: ReverseTranscription-Polymerase Chain Reaction; SPSS: Statistical Package for the Social Sciences; STD: Sexually Transmitted Disease
}

\author{
Acknowledgments \\ Authors would like to express gratitude to supervisors, data collectors, and \\ study participants. The Authors also acknowledge Southern Medical \\ University and Guangdong Dermatology Hospital for funding and securing \\ the ethical clearance, respectively. \\ Funding \\ This study has been funded by Southern Medical University, China.
}

\section{Availability of data and materials}

The datasets used in this study are available from the corresponding author upon request.

\section{Authors' contributions}

WT and ST have contributed in the design, data analysis, thesis write-up, manuscript development, and edition. WY has contributed in the data collection process, analysis, thesis write up, and edition. The final manuscript is reviewed and approved by all authors.

\section{Ethics approval and consent to participate}

Ethical clearance was obtained from the Research Review Committee from Guangdong Dermatology Hospital. The participants were enrolled in the study after obtaining written informed consent.

\section{Consent for publication}

Not applicable.

\section{Competing interests}

The authors declare that they have no competing interests.

\section{Publisher's Note}

Springer Nature remains neutral with regard to jurisdictional claims in published maps and institutional affiliations.

\section{Author details}

'Department of Population Health, College of Health Sciences, Debre Tabor University, Post office box: 272, Debre Tabor, Ethiopia. ${ }^{2}$ Department of Epidemiology, School of Public Health, Southern Medical University, Guangzhou, China. ${ }^{3}$ Chinese center for disease control and prevention, Beijing, China.

Received: 6 January 2019 Accepted: 8 April 2019

Published online: 25 April 2019

\section{References}

1. Stapleton JT, Foung S, Muerhoff AS, Bukh J, Simmonds P. The GB viruses: a review and proposed classification of GBV-A, GBV-C (HGV), and GBV-D in genus Pegivirus within the family Flaviviridae. J Gen Virol. 2011;92(2):233-46.

2. Simons J, Pilot-Matias T, Leary T, Dawson G, Desai S, et al. Identification of two flavivirus-like genomes in the GB hepatitis agent. Proc Natl Acad Sci U S A. 1995;92:3401-5.

3. Xiang J, Nschmann S, Schmidt W, Shao J, Stapleton JT. Full-length GB Virus C (hepatitis G Virus) RNA transcripts are infectious in primary CD4-positive T cells. J Virol. 2000;74(19):9125-33.

4. Feng $Y$, Zhao W, Feng $Y$, Dai J, Li Z, Zhang $X$, et al. A novel genotype of GB virus $C$ : its identification and predominance among injecting drug users in Yunnan, China. PLoS One 2011:6(10):e21151.

5. Muerhoff AS, Leary TP, Sathar MA, Dawson GJ, Desai SM. African origin of $G B$ virus $C$ determined by phylogenetic analysis of a complete genotype 5 genome from South Africa. J Gen Virol. 2005;86(6):1729-35.

6. Sathar MA, York DF, Gouws E, Coutsoudis A, Coovadia HMGB, Virus Type C. Coinfection in HIV-infected African mothers and their infants, KwaZulu Natal, South Africa. Clin Infect Dis. 2004;38:405-9.

7. Muerhoff SA, Simons JN, Leary TP, Erker JC, et al. Sequence heterogeneity within the S-terminal region of the hepatitis GB virus $C$ genome and evidence for genotypes. J Hepatol. 1996;25:379-84.

8. Anggorowati N, Yano Y, Subronto YW, Utsumi T, Heriyanto DS, Mulya DP, et al. GB virus C infection in Indonesian HIV-positive patients. Microbiol Immunol. 2013;57(4):298-308. 
9. Liu Z, Li L, Chen Z, Xu M, Zhang T, Jiao Y, et al. Prevalence of GB virus type C viraemia in MSM with or without HIV-1 infection in Beijing, China. Epidemiol Infect. 2012;140(12):2199-209.

10. Naito $\mathrm{H}$, Hayashi $\mathrm{S}$, Abe K. The entire nucleotide sequence of two hepatitis $\mathrm{G}$ virus isolates belonging to a novel genotype: isolation in Myanmar and Vietnam. J Gen Virol. 2000;81:189-94.

11. Xing-Tai W, Hui Z, Hai-Bo S, He-Min L, Hua-Yuan Z, Yang Y. Partial sequencing of 5 'non-coding region of $7 \mathrm{HGV}$ strains isolated from different areas of China. World J Gastroenterol. 1999;5(5):432-4.

12. Christensen PB, Fisker N, Mygind LH, Krarup HB, Wedderkopp N, Varming K, et al. GB virus $C$ epidemiology in Denmark: different routes of transmission in children and low- and high-risk adults. J Med Virol. 2003;70(1):156-62.

13. Paternoster D, Serena A, Santin M, Marchiori S, Surico N, Amoruso E, et al. $G B$ virus $C$ infection in pregnancy: maternal and perinatal importance of the infection. Eur J Obstet Gynecol Reprod Biol. 2009:144(2):115-8.

14. Ramia SR, Mokhbat J, Sibai A, Klayme S, Naman R. Exposure rates to hepatitis C and $\mathrm{G}$ virus infections among HIV-infected patients:evidence of efficient transmission of HGV by the sexual route. Int J STD AIDS. 2004;15:463-6.

15. Lefrère J-J, Sender A, Mercier B, Mariotti M, Pernot F, et al. High rate of GB virus type C/HGV transmission from mother to infant. Transfusion. 2000;40:602-7.

16. Ramezani A, Mohraz M, Vahabpour R, Jam S, Banifazl M. Frequency of hepatitis G Virus infection among HIV positive subjects with parenteral and sexual exposure. J Gastrointestin Liver Dis. 2008;17(3):269-72.

17. Berzsenyi MD, Bowden DS, Bailey MJ, White C, Coghlan P, Dudley FJ, et al. Male to male sex is associated with a high prevalence of exposure to $G B$ virus C. J Clin Virol. 2005;33(3):243-6.

18. Lau D, Miller K, Detmer J, Kolberg J, Herpin B, Metcalf J, et al. Hepatitis G Virus and human immunodeficiency Virus coinfection. J Infect Dis. 1999;180:1334-7.

19. Xiao W, Lin F, Sun P, Ma L, Li C. Detection of GB virus C/hepatitis G markers in Chinese voluntary blood donors. Braz J Infect Dis. 2014;18(3):352-3.

20. Li G, Ma HH, Lau GK, Leung YK, et al. Prevalence of hepatitis G virus infection and homology of different viral strains in southern China. World J Gastroenterol. 2002;8(6):1081-7.

21. Oubiña JR, Mathet $V$, Feld M, Della Latta MP, Ferrario D, et al. Genetic diversity of GBV-C/HGV strains among HIV infected-IVDU and blood donors from Buenos Aires, Argentina. Virus Res. 1999;65:121-9.

22. Jogeda EL, Huik K, Pauskar M, Kallas E, Karki T, Des Jarlais D, et al. Prevalence and genotypes of GBV-C and its associations with HIV infection among persons who inject drugs in Eastern Europe. J Med Virol. 2017:89(4):632-8.

23. Saitoh H, Moriyama M, Matsumura H, Goto I, Tanaka N, Aarakawa Y. The clinical significance of GBV-C/HGV exposure in C-viral chronic liver disease and blood donors. Hepatol Res. 2002;22:288-96.

24. Noguchi S, Sata M, Suzuki H, Ohba K, Mizokami M, Tanikawa K. GB virus C (GBV-C)/hepatitis G virus (HGV) infection among intravenous drug users in Japan. Virus Res. 1997:49:155-62.

25. Masuko K, Mitsui T, Iwano K, Yamazaki C, et al. Infection with hepatitis gb virus C in patients on maintenance hemodialysis. N Engl J Med. 1996;334:1485-90.

26. Bhanich Supapol W, Remis RS, Raboud J, Millson M, Tappero J, Kaul R, et al. Mother-to-child transmission of GB virus $C$ in a cohort of women coinfected with GB virus C and HIV in Bangkok, Thailand. J Infect Dis. 2009;200(2):227-35.

27. Lole KB, Bollinger RC, Paranjape RS, et al. Full-length human immunodeficiency Virus Type 1 genomes from subtype C-infected Seroconverters in India, with evidence of Intersubtype recombination. J Virol. 1998;73(1):152-60.

28. Kennedy K, Tong CYW, Beeching NJ, Lamden K, Williams H, Mutton KJ, et al. Hepatitis G Virus infection in drug users in Liverpool. J Infect. 1998;37:140-7.

29. Hattori J, Ibe S, Nagai H, Wada K, et al. Prevalence of infection and genotypes of GBV-C/HGV among homosexual men. Microbiol Immunol. 2003:47(10):759-63.

30. Neibecker M, Schwarze-Zander C, Rockstroh JK, Spengler U, Blackard JT. Evidence for extensive genotypic diversity and recombination of $G B$ virus $C$ (GBV-C) in Germany. J Med Virol. 2011;83(4):685-94.

31. Wu H, Padhi A, Xu J, Gong X, Tien P. Intra-host diversity and emergence of unique GBV-C viral lineages in HIV infected subjects in Central China. PLoS One. 2012;7(11):e48417.

32. Lu L, Ng MH, Zhou B, Luo H, et al. Detection and genotyping of GBV-C/HGV variants in China. Virus Res. 2001;73:131-44.

33. Moriyama M, Zi-Yi Z, Longren W, Xueqing W, et al. Clinicoepidemiological study of GBV-C/HGV infection inTokyo metropolitan, and Nanjing and Yanbian cities in the People's republic of China. Hepatol Res. 2001;21:268-79.
34. Maidana MT, Sabino EC, Kallas EG. GBV-C/HGV and HIV-1 coinfection. BJID. 2005:9(2):122-5.

35. Alvarado-Mora MV, Botelho L, Nishiya A, Neto RA, Gomes-Gouvea MS, Gutierrez MF, et al. Frequency and genotypic distribution of GB virus $C$ (GBV-C) among Colombian population with hepatitis B (HBV) or hepatitis C (HCV) infection. Virol J. 2011:8:345

36. Muerhoff AS, Smith DB, Leary TP, Erker JC, Desai SM, Mushahwar IK. Identification of GB Virus C variants by phylogenetic analysis of 59untranslated and coding region sequences. J Virol. 1997;71(9):6501-8.

37. Muerhoff AS, Dawson GJ, Desai SM. A previously unrecognized sixth genotype of $\mathrm{GB}$ virus $\mathrm{C}$ revealed by analysis of $5^{\prime}$-untranslated region sequences. J Med Virol. 2006;78(1):105-11
Ready to submit your research? Choose BMC and benefit from:

- fast, convenient online submission

- thorough peer review by experienced researchers in your field

- rapid publication on acceptance

- support for research data, including large and complex data types

- gold Open Access which fosters wider collaboration and increased citations

- maximum visibility for your research: over $100 \mathrm{M}$ website views per year

At BMC, research is always in progress.

Learn more biomedcentral.com/submissions 